\title{
The Impact of Social Comparison on Accountants' Job Satisfaction and Turnover Intention in Hanoi, Vietnam
}

\author{
Dinh Thi Thanh Hai \\ Faculty of Accounting and Auditing \\ Hanoi University of Industry \\ Hanoi, Vietnam \\ dinhthithanhhai@haui.edu.vn
}

\author{
Hoang Khac Lich \\ University of Economics and Business \\ Vietnam National University, Hanoi \\ Hanoi, Vietnam \\ lichhk@vnu.edu.vn
}

\begin{abstract}
Corporate accountants might be faced with many ethical dilemmas and pressures, some of which are complex and difficult to resolve. Besides, they tend to compare themselves to others in terms of their successes at work. These comparisons may lead to their dissatisfaction and turnover intention. The purpose of this study is to explore the social comparison of accountants working in Hanoi affects their satisfaction and their turnover intention. This study uses quantitative research to analyze data collected from 243 accountants working in Hanoi. Respondents completed measures of upward comparisons, downward comparisons, job satisfaction, and turnover intention. Research results showed that social comparisons affect accountants' job satisfaction and turnover intentions. The upward comparison was found to be positively related to job satisfaction and negatively related to turnover intention. The downward comparison was found to be negatively related to job satisfaction and positively related to turnover intention. Base on the results of collected data analysis, several solutions are suggested for enterprises to improve satisfaction levels of accountants and reduce their turnover intention as the solution of designing job descriptions, solution of building up a standard system of employee appraisal, solutions of building a culture of employee respect and encouragement. The measures created to assess the degree to which individuals make downward and upward social comparisons when assessing their career progress should be tested in additional occupations and studies. Future research should investigate how social comparisons influence career attitudes beyond considering feelings of relative deprivation.
\end{abstract}

Index Terms-Social comparison, job satisfaction, turnover intention, accountants.

\section{INTRODUCTION}

$\mathrm{H}$ ANOI is the capital and the second-largest city in Vietnam. Being located in the northern critical economic region, Hanoi is a dynamic economy center and an essential economic leading city of the North and the whole country. The People's Committee of Hanoi assesses that the city has improved the business environment, supported and developed enterprises, and increased production capacity from 2016 through 2020. The People's Committee of Hanoi also set out the economic development plan for the period of 2021-2025, which emphasizes the effective implementation of external activities and international integration while also enhancing the quality and efficiency of human resources usage in all fields.

Among all the properties of enterprises, human resource is the most significant property, especially those working in fi- nance and accounting. The reason is that all financial and economic information of the enterprises is analyzed and processed by the accounting department. Managers can keep track of business and production activities through the accounting department to evaluate further business development decisions. However, accountants are often under job stress which consequently results in their dissatisfaction. Moreover, one of the most crucial concerns in personnel management is making a convenient, fair, self-motivational working environment.

There are many external and internal factors affecting employees' job satisfaction and their commitment to their organizations. Among those factors, Kulik and Ambrose [1] researched that an individual's attitude is affected by peer pressure. They usually compare their salary, bonus, benefits and other promotional opportunities with each other. Besides, managers usually compare the staff's working effectiveness to appraise the operational performance [2]. Understanding the social comparison of each individual in a particular situation can contribute to decisions improving employees' job satisfaction as well as their commitment with the organization. Acknowledging the relationship between social comparison, staffs' job satisfaction, and the organization commitment will help business managers find solutions to push the working motivation and increase the operational performance of employees.

On that basis, this study will apply the theory of social comparison to study the influence of upward and downward peer comparisons of accountants on their turnover intention.

\section{Literature Review}

\section{A. Empirical Research}

It is necessary to have an accounting information system of many years to compare, evaluate the financial situation of an enterprise, and predict future developments. Therefore, the personnel stability of the finance-accounting department is vital for enterprises. Based on the desire of enterprises to retain qualified accountants, Many researches have been conducted on the factors that influence accountant job satisfaction and turnover intentions. Chatzoglou and his fellows [3] have researched a model to check the job satisfaction of accountants working for various companies in the region of East Macedonia, Greece. Research results show that organi- 
zational and professional engagement factors such as working motivation and job features impact the job satisfaction of accountants. In the factor of working motivation for accountants, scales are used to measure the salary and self-motivation of accountants based on comparison and appraisal of their job performance. Koh, Ong, and Samuel [4] built a research model with three groups of factors affecting job satisfaction of accounting and auditing professionals in Malaysia, namely physical factors, psychological factors, and environmental factors. The results of data analysis indicate that remuneration, the relationship between supervisors and colleagues, job security, opportunities for improvement, leadership style, and organizational culture are critical factors in accountants' job satisfaction. According to this research, job satisfaction also appears to buffer not only the link between supervisors and colleagues and organizational commitment but also the relationship between job security and employee loyalty. In a study done by [5], accountants working for various organizations in Ghana were asked to rate their job satisfaction and turnover intentions. The authors built a research model including independent factors affecting job satisfaction of accountants: salary and bonus, working conditions, autonomy at work, relationship at work, and opportunity to use communication skills and ability. In the studies on the career satisfaction and turnover intentions of accountants, there is no research that mentions the factor of social comparison.

Some previous studies implemented the use of social comparison theory to self-assess job satisfaction and turnover intention. For example, in [6], the author applied social comparison theory to the study of managers in the United States evaluating their career development to other individuals' performance. Research results indicate that social comparisons affect the intention of enterprise change and the job satisfaction of managers. Their turnover intention and work satisfaction are negatively impacted by upward comparison. Their turnover intention and work satisfaction suffer as a result of the downward comparison. Later, some studies use comparative theory in appraising employee performance, such as [7], [8], the research results of these studies show that social comparison orientation is positively related to job performance (performance in each specific task and overall efficiency). However, there has not been any research on social comparison affecting the group of employees in the accounting department of enterprises.

There have been some studies about the influence of social comparison on employee satisfaction and resignation intention through the overall previous research, but not for accountants. On the contrary, there are many studies on accountants' satisfaction level and turnover intention, but not for social comparison factors. Therefore, this research focuses on the effect of social comparison on the turnover intention of accountants.

\section{B. Social Comparison Theory}

The social comparison theory was first developed by Festinger [9] to reflect the motivation for an interpersonal comparison. The interpersonal comparison is caused by self-evaluation, self-improvement, self-enhancement. An individual usually tends to desire an accurate view of his capabilities and position in the organization, thus performing a self-evaluation. Self-improvement reflects an individual's desire of improving himself, and it is also both a motivation and a direction to find ways to improve his performance at work. Self-enhancement plays the role of protecting or enhancing the personal image. These reasons are closely connected. When an individual can self-evaluate, he will have accurate information about his current position and capacity. On that basis, he can ultimately make self-improvement. In addition, self-improvement can satisfy the motivations of self-enhancement.

Research by Wood [10] has indicated that when carrying on social comparison, an individual can both compare oneself with more successful others (upward comparison) as well as worse-off others (downward comparison).

In studies on the affection of social comparison on individuals in the process of self-improvement, Buunk and Gibbons [11] have indicated that upward comparison is closely connected to the self-improvement motivation of an individual, as it can help that person learn from more successful and capable others. In addition, upward comparison can create positive role models, helping inspire individuals to make comparisons and more efforts. Therefore, when the motivation to try better is consistent with the employees' goals, they will have an upward comparison [12].

Downward comparison or self-comparison to worse-off others is often related to increased self-motivation [11]. Downward comparison helps each individual feel better about themselves and their status. Wood and Taylor [13] assert that individuals motivated to maintain and increase selfsatisfaction tend to have a downward comparison.

According to [1], individuals use upward and downward comparisons at different levels because most of them will meet better individuals and worse-off others. According to researchers, individual factors get connected with specified groups of people as a result of socialization. Because upward and downward comparisons are frequently made in the same direction, the tendency of social comparison can affect an individual's attitude towards one's career [14]. Buunk [15] proved that the frequency of upward or downward comparisons plays an essential role in understanding how individuals assess their careers. Therefore, the social comparison has been proposed as a predictor of job satisfaction and compensation expectation [16]. Each person's sentiments about their job or organization are influenced not just by their genuine organizational goals, but also by the social comparison criteria they employ [14]. On this basis, the study will explore the effect of social comparisons on an individual's intention to change jobs.

Various researchers have developed the concept of job satisfaction. In one of the most popular concepts in research [17], researcher defined job satisfaction as a happy or positive emotional working state or working experience appraisal of an employee. According to [18], job satisfaction is defined as the feeling and emotional response to various aspects of an employee's job. With the same point of view, Price [19] also defined job satisfaction as a level in which employees perceive and have positive orientations towards employment in the organization. 
According to [20], a qualified organization is demonstrated by paying attention to humanity, training human resources, caring about employees' happiness and providing them with happy workplaces. He also emphasized the importance of human resources in creating a production environment with outstanding efficiency. Juran [21] also defined that an increased level of employee job satisfaction will benefit the organization in terms of both quality and productivity. Therefore, the study of employee satisfaction at work will help leaders get the real needs, the things that create satisfaction and dissatisfaction, disagreement of employees in the organization. Therefore, executives may develop, adapt and supplement personnel policies of the company within the authorized framework to improve job performance and employees in order to assure quality and sustainable staff. The enhancement of personnel policies will better match the aspirations of employees, providing the business with an opportunity to recruit and retain exceptional staff. The stable, highquality human resources of an organization will ensure its position in the market and create a foundation for sustainable development.

The intention of changing a job or workplace is the intentional desire to leave an organization. According to [22], an employee's turnover intention is the desire to quit their present work and seek employment elsewhere. According to [23] turnover intentions are an important stage and a measure of actually leaving the current job voluntarily. The intention hereby means that before actually leaving the current work environment, these people have made a conscious decision.

The concept of turnover intention reflects an employee's attitude towards an organization, demonstrating the possibility of an employee's resignation in the near future. According to [24], The intention to quit jobs is commonly reflected in three cognitive factors: the want just to change jobs, the desire to look for another work or organization, and the willingness to better occupations. Resignation is always a focus and interest matter in an organization. Resignation intention is the last cognitive stage in leading to actual resignation action and is a crucial decision-oriented factor for employee's leaving or staying in the organization [25]. When an employee resigns, the performance of the remains in the organization will be seriously affected. They have to take account of the working burden of leavers, so they are overloaded, resulting in reducing job satisfaction. Consequently, the chain reactions will influence the resignation consideration of the remains if the organization does not take any timely measures. Thus, when employees resign, there are many risks in an organization. Turnover intention is an employee's intention before their official resignation. The willingness, capacity, and preparation to resign are all part of this goal. Although the turnover intention is not the actual conduct, managers may understand and forecast the actual resignation behavior by studying the turnover intention in order to plan for workers to quit the company or move employees.

\section{Hypothesis and Research Method}

\section{A. Hypothesis}

According to [15], individuals who have a tendency of upward comparison frequently will focus on how others do bet- ter than them and have behavior of new job search more than those who have a regular downward comparison. Although an upward comparing individual can admire others better, this can induce envy and inadequacy, resulting in turnover intention [26].

In contrast, Finegold et al. [27] have shown that individuals who focus on their career achievements more than their colleagues are less likely to leave their organization. In addition, the downward comparison helps individuals improve their mood and job satisfaction resulting in decreasing the turnover intention [28].

In the study [6], it was demonstrated that social comparison affects employee satisfaction and turnover intention. In this study, the upward comparison has a negative impact on employee job satisfaction, but the downward comparison has a positive impact. In contrast, the upward comparison has a positive influence on the turnover intention, but the downward comparison has a negative influence on the turnover intention of employees.

According to the hypothesis of previous studies, the author proposes the following research hypotheses:

H1a: The upward comparison has a negative impact on the job satisfaction of accountants in Hanoi.

H1b: The downward comparison has a positive impact the on job satisfaction of accountants in Hanoi

H2a: The upward comparison has a positive impact on the turnover intention of accountants in Hanoi.

$\mathrm{H} 2 \mathrm{~b}$ : The downward comparison has a negative impact on the turnover of accountants in Hanoi.

\section{B. Research Method}

The author uses the quantitative method as the primary research method. The author inherits the study [6] and professional characteristics of accounting to build up a scale for the influencing factors: upward comparison, downward comparison and the job satisfaction of accountants. The upward comparison consists of four items: contrast your career with that of someone in a higher position, assess development by comparison with more successful people, motivated to achieve success is more similar to more successful people, evaluate career success based on comparison with more successful people. The downward comparison consists of four items: consider your success rather than your colleagues when evaluating your career, I am satisfied with myself when comparing my achievements with colleagues, I perceive myself as more successful than my colleagues, evaluate career success based on comparison with less successful people. The job satisfaction consists of four items: I am receiving a higher salary compared to people working in the same position in other companies, I was promoted to hold a management position in the company, I am appreciated in the field in which I work, I got promoted faster than my colleagues. The author inherits the study [29] and the working context of accountants in Hanoi to build up a scale for the target factor of turnover intention. This factor consists of four items: planning to change jobs within the next six months, looking for a new job, thinking of moving to another organization, turnover if possible.

The survey subjects were current accountants in small and medium enterprises in Hanoi city to supply the required in- 
formation for the research. This study aims to test the scales and research hypotheses using the 5-level Likert scale to design the questionnaire. First, a preliminary survey was conducted on 50 accountants in small and medium commercial enterprises in Hanoi to detect mistakes in the preliminary questionnaires from qualitative research. After that, the authors continue to correct the mistakes to have a formal interview table and conduct formal quantitative research. The results of 26 preliminary analyses indicated that the scales were quite good, with a confidence of more than 0.75 . Therefore, these 50 samples continued to be used as part of the formal survey and the questionnaire without further editing. The authors sent the questionnaire in 3 ways: sending online questionnaires via Google Form, sending them by email, and distributing the pre-printed questionnaire directly. The authors have collected information with 300 samples to ensure the necessary sample size. Survey subjects are employees in Hanoi's small and medium commercial enterprises, and the survey duration was from March 2021 to April 2021.

\section{Results and Discussion}

After the survey duration, the authors received 252 answer sheets, of which 243 were valid and full of information corresponding to 243 samples used. With 16 observed variables, this number of samples is completely reliable in the statistics aspect. These valid questionnaires were coded by SPSS and AMOS 20 software for analysis.

\section{A. Testing the Reliability of the Scale}

The Cronbach Alpha coefficient was used to test the scale's reliability, with the goal of eliminating variables having a corrected item-total correlation of less than 0.3. Criteria choose the scale with the reliability Cronbach's Alpha greater or equal 0.6 [30]. Cronbach's Alpha of the component scales is presented in table 1 .

TABLE 1

SUMMARY OF TESTING CRONBACH'S ALPHA

\begin{tabular}{|l|c|c|c|}
\hline \multicolumn{1}{|c|}{ Factors } & $\begin{array}{c}\text { Numb } \\
\text { er of } \\
\text { Items }\end{array}$ & $\begin{array}{c}\text { Corrected } \\
\text { item - total } \\
\text { correlation }\end{array}$ & $\begin{array}{c}\text { Cronbach } \\
\text { 's Alpha }\end{array}$ \\
\hline Upward comparison & 4 & 0.706 & 0.869 \\
\hline Downward comparison & 4 & 0.623 & 0.819 \\
\hline Job satisfaction & 4 & 0.720 & 0.886 \\
\hline Turnover intention & 3 & 0.740 & 0.874 \\
\hline
\end{tabular}

After testing the scale for the factors of upward comparison, downward comparison, and job satisfaction, Cronbach's Alpha coefficient is more than 0.6 , and all observed variables have a corrected item-total correlation that is more than 0.3 but less than Cronbach's Alpha. Thus, all of these scales meet their reliability. When testing the scale for the factors of turnover intention the initial 4 scales, Cronbach's Alpha value is more than 0.6 , as shown., but the item TURN4 has a correlation coefficient with the corrected item-total correlation of 0.064 (lower than 0.3), so it should be eliminated from the research models. After eliminating the observed variable TURN4, the Cronbach's Alpha value is 0.874 (greater than 0.6) and the corrected item-total correlation of remaining items of the factor of the turnover intention are all greater than 0.3 , so meeting the reliability.

\section{B. Exploratory Factor Analysis}

The component analysis was performed on 15 items of the scales in the study model based on the results of the aforesaid scale's reliability analysis. (after eliminating TURN4)

Obtaining the coefficient $\mathrm{KMO}=0.830>0.5$ and the Barlett's test has the Chi-Square value $=1894.157$ with the significant level $\mathrm{Sig}=0.000<0.05$, indicating that the factor analysis is appropriate. Simultaneously, the total variance extracted by the Principal Axis Factoring method is $63.866 \%>$ $50 \%$, indicating that these extracted factors explain $63.866 \%$ of the variation of the data set, and the Eigenvalues = $1.328>1$ is qualified to factor analysis.

TABLE 2

SUMMARY OF FACTOR ANALYSIS

\begin{tabular}{|c|c|c|c|c|}
\hline \multirow[t]{2}{*}{ Items } & \multicolumn{4}{|c|}{ Factors } \\
\hline & 1 & 2 & 3 & 4 \\
\hline SAT3 &, 885 & & & \\
\hline SAT1 &, 840 & & & \\
\hline SAT2 & ,808 & & & \\
\hline SAT4 &, 724 & & & \\
\hline UP4 & & 921 & & \\
\hline UP2 & & ,773 & & \\
\hline UP1 & & ,752 & & \\
\hline UP3 & & ,703 & & \\
\hline DOWN3 & & & ,858 & \\
\hline DOWN4 & & & ,705 & \\
\hline DOWN2 & & & 675 & \\
\hline DOWN1 & & & ,667 & \\
\hline TURN1 & & & &, 890 \\
\hline TURN3 & & & &, 810 \\
\hline TURN2 & & & &, 801 \\
\hline \multicolumn{4}{|c|}{ KMO measure of sampling Adequacy } & $\mathbf{0 , 8 3 0}$ \\
\hline \multicolumn{4}{|l|}{ Sig. } & $\mathbf{0 , 0 0 0}$ \\
\hline \multicolumn{4}{|c|}{ Eigenvalue } & 1,328 \\
\hline \multicolumn{4}{|c|}{ Total variance explained } & 63,866 \\
\hline
\end{tabular}

We can see that the items match the following constraints based on table 3 , a rotation matrix table created using the Promax rotation method:

Convergent value: The items are grouped together with the factor loadings in the same column with the same scale as the initially proposed scale.

Discriminant value: The items have just one-factor loading that is all more than 0.5 , indicating that they should have discriminatory value with practical importance and may be used to design a regression model to test the initial hypothesis.

\section{Confirmatory Factor Analysis}

A critical model in which the research concepts are freely related to each other was established to test all the concepts in this research [31]. The results of CFA factor analysis for the critical model, as follows:

Test for unidirectionality and coherence with data

To test the measurement model, CFA by AMOS 20 was performed by the ML method, which is the most popular method to estimate parameters in SEM [32]. Figure 1 above shows the output path diagram of the CFA model, and accordingly the overall coherence statistics in the following table:

The results of CFA analysis show that Chi-square statistical value in this model is 130.321 with 84 degrees of free$\operatorname{dom}(\mathrm{p}=0.001), \mathrm{CMIN} / \mathrm{df}=1.551<3$. In addition, other indicators should be considered such as GFI; IFI; TLI; CFI IFI, 


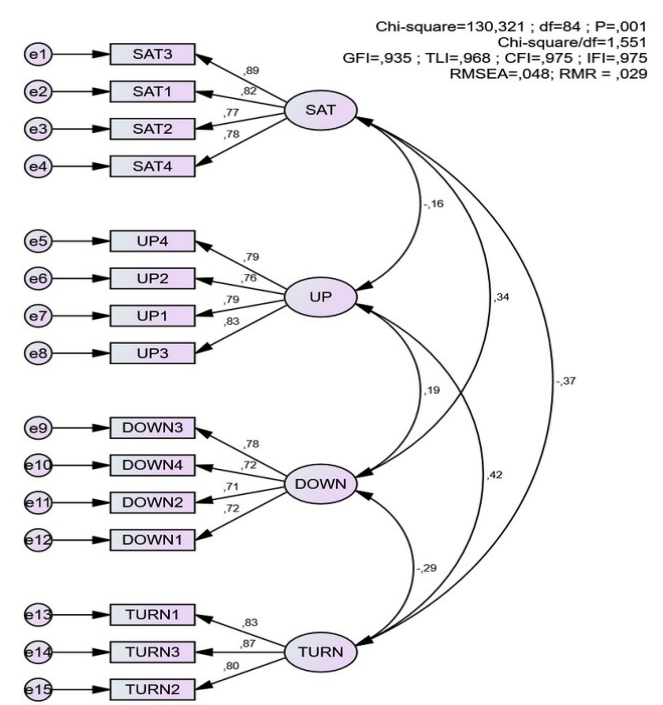

Fig.1: Results CFA the enterprise's ability to access credit (normalized)

TABLE 3

MODEL FIT SUMMARY

\begin{tabular}{|c|c|}
\hline Model fit & Value \\
\hline CMIN/df & 1,551 \\
\hline RMSEA & 0,048 \\
\hline RMR & 0,029 \\
\hline GFI & 0,935 \\
\hline IFI & 0,975 \\
\hline NFI & 0,933 \\
\hline CFI & 0,975 \\
\hline TLI & 0,968 \\
\hline
\end{tabular}

NFI being all greater than 0.9 and RMSEA $=0.048<0.08$ and $\mathrm{RMR}=0.029<0.08$. Therefore, the scale in the model achieves unidirectionality, and the market data is coherent with the model.

\section{Test the convergence value of the scale}

The scale reaches convergence value if the standardized regression weights are all higher than 0.5 and the variance extracted is $\geq 0.50 \quad$ [31]. Table 4 shows that the observed variables' standardized regression weights are all substantial. The smallest is also $0.709>0.5$, and the variances extracted are $\geq 0.50$ so it can be concluded that the scales of the research concepts all reached convergent value. The results of testing the convergence value of the model are presented in the following table.

Test the discriminant value of the scale

The correlation coefficients with standard deviation show all are different from 1 (table 5). In other words, the scales reach a discriminant value.

With the above test results, the developed critical CFA model is coherent with the collected data and has statistical significance. Therefore, it is qualified to analyze the SEM linear structure model to prove the hypothesis of the study.

\section{Structural Equation Modeling}

To assess the study theoretical model, structural equation modeling (SEM) is utilized. This approach has many more benefits than typical multivariable regression since it may be
TABLE 4:

TEST THE CONVERGENCE VALUE OF SCALE

\begin{tabular}{|lll|r|}
\hline & & & Estimate \\
\hline SAT3 & $<---$ & SAT &, 890 \\
SAT1 & $<---$ & SAT &, 822 \\
SAT2 & $<---$ & SAT &, 769 \\
SAT4 & $<---$ & SAT &, 775 \\
UP4 & $<---$ & UP &, 790 \\
UP2 & $<---$ & UP &, 763 \\
UP1 & $<---$ & UP &, 789 \\
UP3 & $<---$ & UP &, 828 \\
DOWN3 & $<---$ & DOWN &, 777 \\
DOWN4 & $<---$ & DOWN &, 724 \\
DOWN2 & $<---$ & DOWN &, 709 \\
DOWN1 & $<---$ & DOWN &, 718 \\
TURN1 & $<---$ & TURN &, 829 \\
TURN3 & $<---$ & TURN &, 875 \\
TURN2 & $<---$ & TURN &, 802 \\
\hline
\end{tabular}

performed after the measurement number. The ML (Maximum Likelihood) estimation approach is used to estimate the model's parameters, similar to how it is used to evaluate scale models via CFA. The SEM model's results are depicted in the figure below.

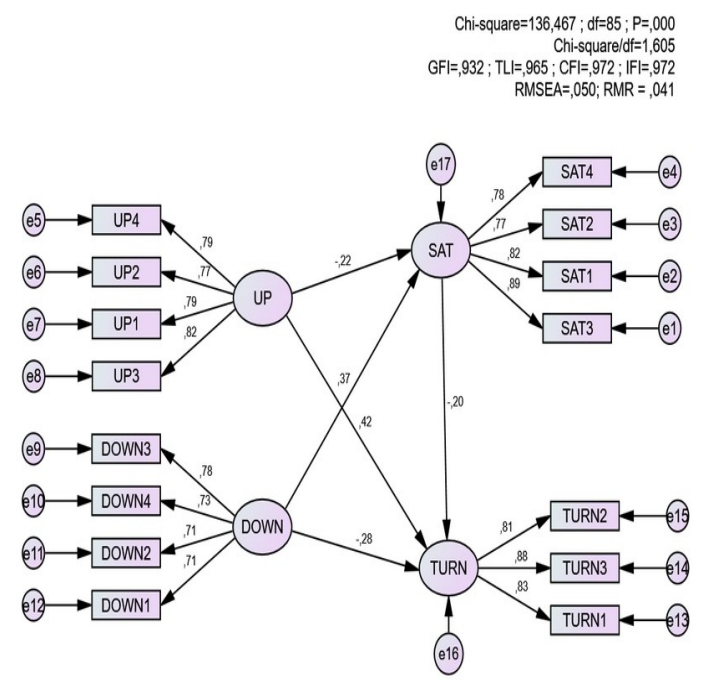

Fig. 2. Result of research model (SEM - standardized estimates)

\section{Test the model coherence}

The model has 85 degrees of freedom, according to the findings of the linear structure analysis, with a Chi-squared

TABLE 5

TEST THE DISCRIMINANT VALUE OF THE SCALE

\begin{tabular}{|c|c|c|c|c|c|c|c|}
\hline & & & $R$ & SE & $1-r$ & CR & $\mathbf{P}$ \\
\hline SAT & $<-->$ & UP & $-0,160$ & 0,109 & $\begin{array}{r}1,16 \\
0\end{array}$ & 10,641 & 0,000 \\
\hline SAT & $<-->$ & DOWN & 0,340 & 0,104 & $\begin{array}{r}0,66 \\
0\end{array}$ & 6,355 & 0,000 \\
\hline SAT & $<-->$ & TURN & $-0,373$ & 0,102 & $\begin{array}{r}1,37 \\
3\end{array}$ & 13,400 & 0,000 \\
\hline UP & $<-->$ & DOWN & $\begin{array}{r}0,18 \\
7\end{array}$ & 0,108 & $\begin{array}{r}0,81 \\
3\end{array}$ & 7,494 & $0,00 \phi$ \\
\hline UP & $<-->$ & TURN & 0,416 & 0,100 & $\begin{array}{r}0,58 \\
4\end{array}$ & 5,815 & 0,000 \\
\hline DOWN & $<-->$ & TURN & $-0,286$ & 0.106 & 1,28 & 12.153 & 0.000 \\
\hline
\end{tabular}


statistical value of 136.467 (P-value $=0.000)$; Chi-squared/ $\mathrm{df}=1.605$ (less than 3 ); hence, we evaluate more meaningful measurement indicators. Besides, we must consider other indicators such as GFI; IFI; TLI; CFI IFI, NFI all greater than 0.9 and $\mathrm{RMSEA}=0.050<0.08$ and $\mathrm{RMR}=0.041<0.08$. Therefore, the scale in the model achieves unidirectionality and the market data is coherent with the model. According to the above criteria, the research model is coherent with the market data. Specifically, the measurement indicators of the coherence level of the model are shown in the following table.

TABLE 6

EVALUATION INDICATOR SYSTEM AND FITTING RESULT OF SEM OVERALL MODEL FIT

\begin{tabular}{|c|c|c|}
\hline & Actual fitting value & Standard \\
\hline $\begin{array}{c}\text { CMIN/ } \\
\text { df }\end{array}$ & 1,605 & $<3$ \\
\hline RMSEA & 0,050 & $<0.08$ \\
\hline RMR & 0,041 & $<0.08$ \\
\hline GFI & 0,932 & $>0.9$ \\
\hline IFI & 0,972 & $\geq 0.9$ \\
\hline NFI & 0,930 & $>0.9$ \\
\hline CFI & 0,972 & $>0.9$ \\
\hline TLI & 0,965 & $>0.9$ \\
\hline
\end{tabular}

Test the relationship between the factors of the model

Table 7 displays the estimated outcomes of the parameters. This indicates that the associations are statistically significant (p less than 5\%).

TABLE 7

UNSTANDARDIZED COEFFICIENTS FOR SEM MODEL

\begin{tabular}{|l|l|l|r|r|r|c|}
\hline \multicolumn{2}{|l}{} & \multicolumn{1}{c|}{$\mathrm{r}$} & \multicolumn{1}{c|}{ SE } & \multicolumn{1}{c|}{ CR } & \multicolumn{1}{c|}{ P } \\
\hline SAT & $<---$ & UP &,- 361 &, 115 & $-3,144$ &, 002 \\
\hline SAT & $<---$ & DOWN &, 401 &, 079 & 5,064 & $* * *$ \\
\hline TURN & $<---$ & UP &, 712 &, 118 & 6,012 & $* * *$ \\
\hline TURN & $<---$ & DOWN &,- 308 &, 080 & $-3,848$ & $* * *$ \\
\hline TURN & $<---$ & SAT &,- 203 &, 071 & $-2,843$ &, 004 \\
\hline
\end{tabular}

However, the unstandardized regression coefficient only shows the positive or negative impact of the independent factor on the dependent factor (indicated $+/-$ ). This has greater relevance in mathematics than in economics since it simply represents the change in the dependent variable when each independent variable changes, as long as the remaining variables remain constant.

To examine the affecting amount of influence ratio of the independent factors on the dependent variable, the standardized regression coefficient is utilized. The larger the value is, the more important the independent variable to the dependent one is. We consider the table of regression coefficients with the normalized beta:

TABLE 8

STANDARDIZED COEFFICIENTS FOR THE SEM MODEL

\begin{tabular}{|lll|r|}
\hline & & & Estimate \\
\hline SAT & $<---$ & UP &,- 215 \\
SAT & $<---$ & DOWN &, 371 \\
TURN & $<---$ & UP &, 418 \\
TURN & $<---$ & DOWN &,- 281 \\
TURN & $<---$ & SAT &,- 200 \\
\hline
\end{tabular}

Referring to Table 8, we see that there is an influence of social comparison on the job satisfaction of accountants: Upward comparison affects job satisfaction with a standardized regression coefficient of -0.215 (negative effect); Downward comparison affects job satisfaction with a standardized regression coefficient of 0.371 (positive effect).

Besides, the SEM results also prove that there is an influence of social comparison on the turnover intention of accountants: Upward comparison affects turnover intention with a standardized regression coefficient of 0.418 (positive effect); downward comparison affects the turnover intention with a standardized regression coefficient of -0.281 (negative effect).

Finally, the SEM results also indicate that there is an impact of job satisfaction on the resignation intention of accountants by the regression coefficient expressing the impacting level of $-0,200$ (negative effect).

\section{Conclusion and Recommendations}

According to the findings, there was a causal association between UP and SAT. The regression coefficient representing this relationship is -0.215 with statistical significance at a significant level of 5\%. Thus, hypothesis H1a is accepted. There is a causal relationship between DOWN and SAT. The regression coefficient of this relationship is 0.371 with statistical significance at the significant level of 5\%. Thus, hypothesis $\mathrm{H} 1 \mathrm{~b}$ is accepted. So in consideration of the size of the regression coefficient, the downward comparison will have a higher influence on job satisfaction than upward comparison.

There is a causal relationship between UP and TURN. The regression coefficient of this relationship is 0.418 , with statistical significance at significant level of $5 \%$. Thus, hypothesis $\mathrm{H} 2 \mathrm{a}$ is accepted. There is a causal relationship between DOWN and TURN. The regression coefficient of this relationship is -0.281 , with statistical significance at significant level of $5 \%$. Thus, hypothesis H2b is accepted. In consideration of the size of the regression coefficient, upward comparison will have a higher influence on the turnover intention than downward comparison.

Based on the research results, business managers can refer to the following implications:

* Solution of designing job descriptions

The human resources department of the enterprise needs to coordinate with the finance-accounting department to design a decentralized management model of the finance-accounting department by the size and workforce of this department. Then, based on the designed management model, the person in charge of accounting needs to develop a detailed job description for each job position in the department.

* Solution of building up a standard system of employee appraisal.

In order to ensure appraisal fairness of the employee performance, it is necessary that enterprises must have a system of specific appraisal and classification standards. For example, for the appraisal of accountants, the human resources department and the accounting department need to work together to develop suitable appraisal criteria for job characteristics, positions and titles.

* Solutions of building a culture of employee respect and encouragement 
Managers should not compare an employee's results directly with better others because it causes pressure on unachieved employee and reduces their job satisfaction.

When an employee's job performance declines with their past performance or their results are under the enterprise's set of standards, managers need to give the employee motivation and find out the reasons to help them complete their tasks if necessary.

Managers should also build a common ideal role model for the employees to encourage and motivate them. The employees should be motivated to achieve the role model's standards when performing the assigned jobs and tasks. Simultaneously, managers need to show employees' possibility of achieving a job promotion if they improve their performance.

\section{REFERENCES}

[1] C. T. Kulik, M.L. Ambrose, "Personal and situational determinants of referent choice," Academy of Management Review, vol. 17, no. 2, pp. 213-237, 1992.

[2] J. Greenberg, C.E. Ashton-James, Ashkanasy N.M, "Social comparison processes in organizations," Organizational Behavior and Human Decision Processes, vol. 102, pp. 22-41, 2007.

[3] P. D. Chatzoglou, E. Vraimaki, E. Komsiou, E. Polychrou, "Factors affecting accountants' job satisfaction and turnover intentions: A structural equation model," in 8th International Conference on Enterprise Systems, Accounting and Logistics, Thassos Island, Greece, Thassos Island, 2011.

[4] S. Y. Koh, T.S. Ong, A.B.Samuel, "The impacts of Physical, Psychological, and environmental factors on employees job satisfaction among public accounting professionals in Malaysia," Asia - Pacific manangement accounting journal, vol. 12, no. 2, pp. 129-15, 2017.

[5] J. S. T. Zotorvie, M.B. Kudo, T.C. Adade, "A Survey of Factors that Influence the Level of Job Satisfaction and Turnover Intention of Professional Accountants in Ghana," International Journal of Academic Research in Business and Social Sciences,, vol. 7, no. 10, pp. 41-56, 2017.

[6] K. A. Eddleston, "The effects of social comparisons on managerial career satisfaction and turnover intentions.," Career Development International, vol. 14, no. 1, pp. 87-110, 2009.

[7] L.T. Dai, R. Xiao, "The influence of social comparison on job performance," Open Journal of Socail Science, vol. 4, pp. 147-151, 2016.

[8] N.S. Gigarasi \& J. Hassaskhah, "The effect of social comparison tendencies on EFL teachers' experience of burnout and instructional self - efficacy," Congent Psychology, vol. 4, pp. 1-21, 2017.

[9] Festinger, "A theory of social comparison process," Human relations, vol. 7, pp. 117-140, 1954.

[10] J.V.Wood, "What is social comparison and how should we study it?," Personality and Social psychology Bulletin, vol. 22, pp. 520-537, 1996.

[11] B.P. Buunk, F.X. Gibbons, "Social comparison; the end of a theory and the emergence of a field.," Oganizational Behauvior and Human Decision Processes, vol. 107, pp. 3-21, 2007.

[12] J.W. Gastorf, J. Suls, G.S. Sanders, "Type A coronary-prone behavior pattern and social facilitation," Journal of Personality and Social Psychology, vol. 38, pp. 773-800, 1980.
[13] J.V.Wood, K.L. Taylor ,"Serving self-reference goal through social comparison. in Suls, J. and Wills, T.A. (Eds), Social Comparison: Contemporary Theory and Research,," Erlbaum Associate, Hillsdale, NJ, pp. 23-50, 1991.

[14] D.J. Brown et al., "Antecedents and consequences of the frequency of upward and downward social comparisons at work," Organization Behavior and Human Dwcision Processes, vol. 102, pp. 59-75, 2007.

[15] B.P. Buunk, R. Zurriaga, V. Gonzalez-Rona, M. Subirats, "Engaging in upward and downward comparisons as a deteeminant of relatice deprivation at work: a longitutdinal study.," Journal of Vocational Behavior, vol. 62, pp. 370-388, 2003.

[16] G.R. Oldham, C.T. Kulik, M.L. Ambrose, L.P. Stepina, J.F. Brand, "Relations between job facet comparisons and employee reactions," Organizational Behavior and Human Decision Process, vol. 38, pp. 2847, 1986.

[17] E.A. Locke, " The Nature and Causes of Job Satisfaction. In: Dunnette, M.D., Ed," Handbook of Industrial and Organizational Psychology, vol. 1, pp. 1297-1343., 1976.

[18] J. Schermerhorn, Management for productivity, Canada: JohnWiley \& Sons, Inc., 1993.

[19] J.L. Price, "Handbook of organizational measurement.," International Journal of Manpower, vol. 18, pp. 303-558, 1997.

[20] K. Ishikawa, What Is Total Quality Control? The Japanese Way., New Jersey: Prentice-Hall, Englewood Cliffs, 1985.

[21] J. Juran, Juran on Leadership for Quality, The Free Press: New York, 1989.

[22] J.C.L. Chew, , Influence of human resources management practices on the retention of core employees of Australia organizations: An empirical study. [Doctoral Thesis]. Murdoch University, 2004.

[23] C. M. Kinnoin, An examination of the relationship between familyfriendly policies and employee job satisfaction, intent to leave, and organizational commitment.. [Performance]. Nova Southeastern University, Florida, 2005.

[24] A. Carmeli, J. Weiberg, "Exploring turnover intentions among three professional groups of employees," Human Resources Development International, vol. 9, no. 2, pp. 191-206, 2006.

[25] M. Mari, Job satisfaction and turnover intention among the skilled personnel in TRIplc berhad. [Master Thesis]. Universiti Utara Malaysia., 2009.

[26] F. E. Diener, Journal of Personality and Social Psychology,, vol. 68, pp. 926-935, 1995.

[27] D. Finegold, S. Mohrman, G.M. Spreitzer, "Age effects on the predictors of technical workers' commitment and willingness to turnover.," Journal of Organizational Behavior, vol. 23, pp. 655-674, 2002.

[28] B. Major, M. Testa, W.H. Bylsma, "Responses to upward and downward social comparisons: the impact of esteem-relevance and perceived control. in Suls, J. and Wills, T.A. (Eds)," Social Comparison: Contemporary Theory and Research, Erlbaum Associates, Hillsdale, pp. 237-260, 1991.

[29] A. Pradana \& I. Salehudin, "Role of work overloas toward turnover intention among newly hired public accountants.," in 8th International conference on Business anD Manangement reseearch, Seoul, South Korea, 7th November 2013, Seoul, 2013.

[30] J.C. Nunnally, I.H. Bernstein, Psychometric theory. (3rd ed.)., New York: McGraw-Hill, 1994.

[31] J.C. Anderson, D.W. Gerbing " Structural Equation Modeling in Practice: A Review and Recommended Two-Step Approach.," Psychological Bulletin,, vol. 103, pp. 411-423., 1988.

[32] K. Schermelleh-Engel, H. Moosbrugger, H. Muller, "Evaluating the fit of structural equation models: tests of significance and goodness-of-fit models.," Methods of Psychological Research Online, vol. 28, pp. 2374, 2003. 